\section{THE ASSOCIATION BETWEEN DURATION TO OPERATION AND MORTALITY RATE IN PENETRATING TRAUMA PATIENTS}

Tawatchai Impool, Pothipong Reungjui , Supaporn Tansura. Division of Trauma, Department of Surgery, Khon Kaen Hospital, Thailand

\subsection{6/injuryprev-2016-042156.596}

Background The duration from emergency department (ED) to operative room (OR) is an important factor to predict the outcome in severe trauma patients. Trauma Fast Track (TFT) policy was established in Khon Kaen Hospital for 5 years. According to this policy, shorter duration from ED to OR (ED time) might be more safe life of the patients.

Methods Cross-sectional analytic study, the patients with penetrating torso and haemodynamic instability who admitted to Khon Kaen Hospital from October 2011 to September 2014 were included. The Fisher exact test were used for data analysis. Results A total of 82 patients were included. Of these, penetrating injury to abdomen and chest were $78 \%$ and $22 \%$, respectively. The mortality rate was $25.6 \%$. The mean ED time were 43 minutes and Injury Severity Score (ISS) were 18.8. The ED time more than 30 minute [odds ratio (OR), 4.1; 95\% confidence interval $(\mathrm{CI}): 1.2-13.6 ; \mathrm{P}=0.021]$, and ISS more than 15 [OR, 9.5; 95\%, CI: 1.1-78.7; $\mathrm{P}=0.021]$ were associated with increase mortality rate.

Conclusions The mortality rate of penetrating injury at torso with haemodynamic instability is significantly associated with duration from ED to OR and ISS. According to this result, unnecessary procedure or intervention at ER should be avoided.

\section{A DESIGN FOR THE EVALUATION OF THE EMERGENCY MEDICAL RETRIEVAL AND TRANSFER SERVICE (EMRTS) CYMRU}

${ }^{1}$ Jane Lyons, ${ }^{2}$ David Rawlinson, ${ }^{1}$ Ronan A Lyons, ${ }^{1}$ Richard J Fry. ${ }^{1}$ Farr Institute, Swansea University, UK; ${ }^{2}$ Clinical Informatics Manager, EMRTS Cymru

\subsection{6/injuryprev-2016-042156.597}

Background Since April 2015 EMRTS provides pre hospital, consultant-led, critical care for people in Wales with life or limb threatening injuries or illness. Consultants and critical care practitioners on air ambulances and $4 \times 4$ emergency response vehicles now deliver emergency department equivalent; time critical; lifesaving treatment on scene and during transfer to hospital. This service covers $95 \%$ of the population by air and $46 \%$ by road within 30 minutes and aims to improve patient survival and outcomes.

Methods Multi-sourced linked datasets are being used in evaluation, including mortality, hospital admission, ED, on scene clinical electronic reporting forms that include incident details, vital signs, and treatments/procedures. Patients will be interviewed six months and one-year post incident for longer-term functional and quality of life outcomes. Data will be anonymized and made available for research and evaluation through the Secure Anonymised Information Linkage (SAIL) facility. WAST (Welsh Ambulance Service Trust) will also provide data to incident to scene and care times. Cases from both pre-EMRTS historical data and EMRTS-offline (restricted flying night/bad weather) will be used as comparators in the evaluation.

Results Data are being assembled for evaluation. The pattern of missions has changed following EMRTS; injury related attendances decreased from $56 \%$ to $51 \%$ and cardiac/respiratory deployments increased from $9 \%$ to $20 \%$. Median response to arrival at scene times are unchanged (15 mins) but arrival at scene to hospital increased from 45 to 64 minutes. Further results on outcomes will be presented.

Conclusions Evaluation is just beginning and will include comparison of survival, resource use and health related quality of life with local and international data.

\section{PSYCHOLOGICAL TRAUMA AFTER ROAD TRAFFIC ACCIDENTS: COIMBRA NETWORKING STRATEGIES FOR EARLY DETECTION}

Ana Dourado*, Vasco Nogueira, João Redondo. Centre for Prevention and Treatment of Psychological Trauma, Department of Psychiatry, Coimbra University Hospital Centre (CHUC), Portugal

\subsection{6/injuryprev-2016-042156.598}

Background Worldwide, about 1.25 million people die each year as a result of road traffic accidents (World Health Organisation's Global Status Report on Road Safety 2015) and as many as 50 million people are injured. In Portugal, last year we have registered about 480 deaths, 2.098 severely injured. Trauma, after road traffic accidents are a major problem of public health, associated with a substantial impact on psychological, social, economic and labour dimensions, both for the victims and for their families.

Description of the problem Road traffic accidents are frequently associated with an increased risk for psychological problems, particularly acute reaction to stress, phobic anxiety, depression, or even a posttraumatic stress disorder. The consequences involve increased medical costs and longer hospitalizations, decreased productivity, help-seeking behaviour. Most of these patients with somatization complains, conversive symptoms, depression, chronic pain, presents a posttraumatic stress disorder (PTSD) not diagnosed.

Results In order to implement appropriate strategies for prevention and treatment and so reducing the risk and impact inherent in the development of psychological disorders, it is essential that the diagnosis is made as soon as possible. The survivors of road traffic accident at risk will be referred to the Centre for Prevention and Treatment of Psychological Trauma before being discharged from the General Hospital: Emergency Room, Surgery, Orthotraumatology or Neurosurgery Wards.

They will be subjected to a brief screening for symptoms of PTSD, dissociative symptoms, anxiety, nightmares and phobias, briefly after the accident and 4 weeks later. This is a challenge that requires a networking efforts for effective prevention.

Conclusions Early identification of people with posttraumatic stress symptoms after a road traffic accident is critical to allow for intervention and prevent greater impairment and restriction.

\section{CLINICIANS' PERCEPTIONS REGARDING THEIR ROLES AND FUNCTIONING WITHIN A NEW ZEALAND REGIONAL TRAUMA SYSTEM}

${ }^{1}$ Bridget Kool* ${ }^{*}$ ' $H$ Henrietta Lee, 'Shanthi Ameratunga, ${ }^{1,2}$ Ross Lawrenson, ${ }^{2}$ Nina Scott, ${ }^{2}$ Grant Christey. ${ }^{1}$ University of Auckland, New Zealand; ${ }^{2}$ Waikato Hospital, New Zealand

10.1136/injuryprev-2016-042156.599

Background The effectiveness of trauma systems in reducing injury mortality is well established. This study aimed to explore 